\title{
Socio-economic determinants of participation in the Lolland-Falster health study
}

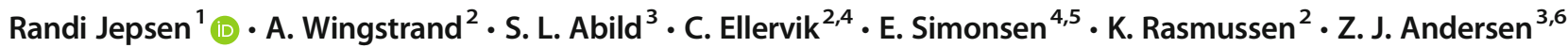

Received: 10 April 2019 / Revised: 16 May 2019 / Accepted: 23 May 2019 / Published online: 1 June 2019

(C) The Author(s) 2019

\begin{abstract}
Aim The Lolland-Falster Health Study (LOFUS) is an ongoing prospective cohort study at Lolland-Falster, one of the most socio-economically disadvantaged areas of Denmark. The aim of this study was to examine the participation rates and socioeconomic determinants of participation in LOFUS, approximately halfway through the data collection.

Subjects and methods LOFUS started in 2016 and should include 20,000 participants from the total of 103,000 inhabitants of Lolland-Falster by the end of 2019. For the participation analyses, we used data on the 36,883 subjects invited between January 2016 and November 2018. For the analyses of determinants of participation, we used data on the 24,283 adults (aged $\geq 18$ years) invited between January 2016 and June 2018, for whom we extracted data on personal income, employment, education, marital status, citizenship, and household type from Danish registers. We used logistic regression to estimate associations between socioeconomic factors and participation, adjusting for age and gender.

Results $34.1 \%$ of invited subjects participated (men: $31.9 \%$, women: $36.4 \%$ ), with the highest rate in women aged $60-69$ years $(47.5 \%)$ and the lowest in women aged $\geq 90$ years $(7.3 \%)$. Odds ratios for participation increased with income, education level, and employment status, and among married persons, Danish citizens, middle-aged persons (aged 50-69 years), and women. Conclusion Subjects with lower socio-economic status were underrepresented halfway through the LOFUS data collection, in line with other cohort studies.
\end{abstract}

Keywords LOFUS $\cdot$ Cohort study $\cdot$ Socio-economic determinants $\cdot$ Education $\cdot$ Occupation $\cdot$ Income

\section{Background}

Electronic supplementary material The online version of this article (https://doi.org/10.1007/s10389-019-01095-z) contains supplementary material, which is available to authorized users.

Randi Jepsen

rjep@regionsjaelland.dk

1 Lolland-Falster Health Study, Centre for Epidemiological Research, Nykøbing F. Hospital, Fjordvej 15, 4800 Nykøbing F, Denmark

2 Data and Development Support, Region Zealand, 4130 Sorø, Denmark

3 Centre for Epidemiological Research, Nykøbing F. Hospital, 4800 Nykøbing F, Denmark

4 Department of Clinical Medicine, University of Copenhagen, 2200 Copenhagen N, Denmark

5 Psychiatric Research Unit, Psychiatry Region Zealand, 4200 Slagelse, Denmark

6 Faculty of Health Sciences, Department of Public Health, University of Copenhagen, 1014 Copenhagen K, Denmark
The Lolland-Falster Health Study (LOFUS) (Jepsen et al. 2018 ) is an ongoing prospective cohort study initiated in 2016 on inhabitants of the two Danish islands Lolland and Falster, also known as Lolland-Falster. Subjects of all ages are recruited from approximately 103,000 inhabitants of this mixed rural-provincial area in south-eastern Denmark, which is considered one of the most socio-economically disadvantaged areas of Denmark, with shorter life expectancy than the rest of the country. LOFUS was designed with the aim to form the basis for research into the causes of the disease burden in Lolland-Falster and for the planning of preventive and healthpromoting interventions. More details about the study design and the content of LOFUS are presented by Jepsen et al. (2018). Briefly, LOFUS is organized as a household-based study where all household members of randomly selected adults (aged 18 years and above) are invited to participate. The data collection encompasses self-administered, age- and gender-specific questionnaires on lifestyle factors, mental and 
physical health, and social factors, a physical examination (anthropometrics, electrocardiography, blood pressure, pulse, saturation, spirometry, hand grip strength, and accelerometerassessed physical activity), and collection of biological samples (blood, urine, saliva, and feces). The data collection started in February 2016, with an estimated 20,000 participants expected by the end of 2019 (Jepsen et al. 2018).

LOFUS is unique in the sense that it focuses on a general population of all ages from a socio-economically disadvantaged area. This sets it apart from some other prominent Danish cohorts, such as the Danish Diet, Cancer and Health cohort (Tjønneland et al. 2007), the Copenhagen City Heart Study (Aguib and Al Suwaidi 2015), and the Danish Nurse Cohort (Hundrup et al. 2012). The Danish Diet, Cancer and Health cohort recruited 57,053 participants from the general population between the ages of 50 and 64 years who resided in the two largest Danish cities, Copenhagen and Aarhus, between 1993 and 1997 and were free of cancer at recruitment. The study achieved participation rates of 35\% (37\% in women and $34 \%$ in men) and documented that participants had higher socio-economic status (higher income, education, and occupation) than non-participants (Tjønneland et al. 2007). The Copenhagen City Heart Study recruited adult subjects aged 20-93 years from the general population living in inner Copenhagen, with a participation rate of $76 \%$ in the first round of the cohort (1976-78), which decreased to $49.5 \%$ in the last/ fourth round in 2001-2003 (Aguib and Al Suwaidi 2015). Both studies included a questionnaire and physical examination. The Danish Nurse Cohort (Hundrup et al. 2012) is an occupational cohort which recruited female nurses who were members of the Danish Nursing Organization in 1993 and 1999 , with participation rates of $86 \%$ and $76 \%$, respectively; however, only a self-administered questionnaire was required, without physical examination.

\section{Aims}

The overall objectives of this study are to present participation rates by age and gender and to examine socio-economic determinants of participation in LOFUS, approximately halfway through the data collection.

\section{Subjects and methods}

\section{Participation in the Lolland-Falster Health Study}

Every person residing in Denmark is uniquely registered in the Danish Civil Registration System (CRS) (Schmidt et al. 2014). The LOFUS database receives daily updates from the CRS on all inhabitants of Lolland-Falster regarding births, deaths, immigration, and moving of residences. Almost daily, index persons aged 18 years and above are randomly selected via the LOFUS database. Their entire households are then randomly allocated to either an invitation or a control group in a 2:1 ratio (Jepsen et al. 2018). In the invitation group, all household members receive individual invitations sent digitally via the CRS-linked mailbox e-Boks, in which Danish residents are enrolled from the age of 15 years (e-Boks 2017). Children between the ages of 0 and 14 years and others with exemption from e-Boks receive invitations by mail. Subjects in the control group are not contacted. The invited subjects can respond via e-Boks, phone, e-mail, or text message. Subjects who do not respond within 14 days receive re-invitations and, after another 14 days of non-response, staff attempt to reach the households by phone call or text message (Jepsen et al. 2018).

In the present study, participation implies having signed the consent to participate and having contributed fully or partially to the physical examination and/or the biological sample collection. Completing the questionnaire only is not an option. Non-participants are subjects who responded that they did not want to participate, whom LOFUS did not manage to reach by telephone call or text message, who died without participating, or who withdrew a previously signed consent. Invited subjects who responded that they might participate later counted as non-participants in the present study but may eventually shift status to participants.

Booking of the physical examination is done by phone, with a choice between three LOFUS locations at LollandFalster. Alternatively, LOFUS staff could visit participants at home with a fully equipped camper in the period from February 2016 to September 2018. Household members have the option to come together for the appointment, and families with young children are encouraged to undergo the examination together to support children's coping with unfamiliar procedures. The participants are encouraged to complete their questionnaires electronically at home prior to the physical examination, but, if needed, they can get help from staff after the physical examination. Paper-based versions are used only if participants cannot master the electronic questionnaire. Completion of the questionnaire is estimated to last min. 15$60 \mathrm{~min}$, depending on age (five different questionnaires: 0 1 years, $2-3$ years, $4-10$ years, filled out by parents, and $11-$ 17 years and $\geq 18$ years, self-administered) and genderspecific number of items. The physical examination takes approximately $1 \mathrm{~h}$ for adults and, depending on their age, 20$45 \mathrm{~min}$ for children (Jepsen et al. 2018).

\section{Study population and socio-economic data}

For the analyses of participation rates approximately halfway through the data collection, we used data on the 36,883 subjects (belonging to 17,000 households) who were selected for invitation to participate in LOFUS between 29 Jan 2016 and 
30 Nov 2018, including information on age, gender, and participation status. For analyses of socio-economic determinants of participation, we used data on the 30,000 subjects who were selected for invitation between 29 Jan 2016 and 1 Jun 2018 and limited the analyses to 24,283 adults of age 18 years and above. This dataset was uploaded to Statistics Denmark, the central Danish authority of official statistics (Thygesen 1995), in accordance with their procedure for secure data management, and was linked to national registers on personal income and transfer payments (Baadsgaard and Quitzau 2011), personal labor market affiliation (Petersson et al. 2011), and education (Jensen and Rasmussen 2011), with individual-level information on a number of demographic, social, and economic factors on all Danish citizens. We extracted information on occupation in 2016 from the Employment Classification Module (in Danish: Arbejdsklassifikationsmodulet or AKM) (Baadsgaard and Quitzau 2011) and classified occupation into seven categories, from the original 19 categories, as shown in the online supplemental additional file 1 . We extracted civil status, type of household, and citizenship in 2016 from the Basic Data Register (in Danish: Grunddata or BEF register), taxable income in 2016 from the Income Register (in Danish: Indkomst or IND), and data on highest achieved education in 2016 from the Education Register (in Danish: Uddannelsesniveau or UDDA).

\section{Statistical analyses}

We calculated age- and gender-specific participation rates by dividing the number of participating subjects by the number of invited subjects and presented it as percentages in Table 1 . We used logistic regression to estimate associations between six socio-economic factors (occupation, civil status, type of household, citizenship, taxable income, and education), one at the time, and participation in LOFUS in the total sample adjusting for age and gender and separately for men and women in age-adjusted models, using the logistic procedure in the Stata 15.0 statistical package. Complete case analyses were performed for each socio-economic factor, giving slightly different numbers of subjects in each analyses, as specified in Table 2. The results are presented as odds ratios (ORs) and 95\% confidence intervals (CIs).

\section{Ethics}

Informed written consent was obtained from all LOFUS participants. Parents/guardians gave consent for participants younger than 15 years of age. The LOFUS study was approved by the Region Zealand's Ethical Committee on Health Research (SJ-421) and the Danish Data Protection Agency (REG-24-2015). LOFUS is registered in Clinical Trials (NCT02482896).

\section{Results}

Halfway through the LOFUS data collection, the overall participation rate for the first 36,883 subjects invited between 29 Jan 2016 and 30 Nov 2018 was 34.1\% (Table 1). The lowest participation rate of $8.1 \%$ was observed in old people aged 90 years and above $(9.5 \%$ in men and $7.3 \%$ in women), followed by $18.6 \%$ in young adults aged $20-29$ years $(15.8 \%$ in men and $22.0 \%$ in women). The highest participation rates were observed for women aged 60-69

Table 1 Participation rates in the Lolland-Falster Health Study by gender and age for 36,883 subjects (17,000 households) invited between 29 Jan 2016 and 30 Nov 2018

\begin{tabular}{|c|c|c|c|c|c|c|}
\hline \multirow[t]{2}{*}{ Age (years) } & \multicolumn{2}{|l|}{ Total } & \multicolumn{2}{|l|}{ Men } & \multicolumn{2}{|l|}{ Women } \\
\hline & Invited, $n$ & Participants, $n(\%)$ & Invited, $n$ & Participants, $n(\%)$ & Invited, $n$ & Participants, $n(\%)$ \\
\hline $0-1$ & 620 & $149(24.0)$ & 326 & $80(24.5)$ & 294 & $69(23.5)$ \\
\hline $2-10$ & 2871 & $900(31.3)$ & 1495 & $455(30.4)$ & 1376 & $445(32.3)$ \\
\hline $11-17$ & 2915 & $834(28.6)$ & 1485 & 409 (27.5) & 1430 & 425 (29.7) \\
\hline $18-19$ & 1034 & $228(22.1)$ & 524 & $108(20.6)$ & 510 & $120(23.5)$ \\
\hline $20-29$ & 3567 & $662(18.6)$ & 1982 & $314(15.8)$ & 1585 & $348(22.0)$ \\
\hline $30-39$ & 3261 & $904(27.7)$ & 1719 & $399(23.2)$ & 1542 & $505(32.7)$ \\
\hline $40-49$ & 4601 & $1633(35.5)$ & 2309 & $725(31.4)$ & 2292 & 908 (39.6) \\
\hline $50-59$ & 5931 & $2424(40.9)$ & 2992 & $1086(36.3)$ & 2939 & $1338(45.5)$ \\
\hline $60-69$ & 5736 & $2644(46.1)$ & 2849 & $1273(44.7)$ & 2887 & $1371(47.5)$ \\
\hline $70-79$ & 4412 & $1761(39.9)$ & 2210 & 897 (40.6) & 2202 & $864(39.2)$ \\
\hline $80-89$ & 1637 & $426(26.0)$ & 757 & $232(30.6)$ & 880 & $194(22.0)$ \\
\hline$\geq 90$ & 298 & $24(8.1)$ & 105 & $10(9.5)$ & 193 & $14(7.3)$ \\
\hline Total & 36,883 & $12,589(34.1)$ & 18,753 & 5988 (31.9) & 18,130 & $6601(36.4)$ \\
\hline
\end{tabular}


Table 2 Distribution of gender and socio-economic parameters among participants and non-participants in the Lolland-Falster Health Study target population $\geq 18$ years of age and invited between 29 Jan 2016 and 1 Jun $2018(N=24,283)$

\begin{tabular}{|c|c|c|c|c|c|c|}
\hline & \multicolumn{2}{|l|}{ Total, $N=24,283$} & \multicolumn{2}{|l|}{ Men, $n=12,357$} & \multicolumn{2}{|l|}{ Women, $n=11,926$} \\
\hline & $\begin{array}{l}\text { Participants, } \\
n=8580\end{array}$ & $\begin{array}{l}\text { Non-participants, } \\
n=15,703\end{array}$ & $\begin{array}{l}\text { Participants, } \\
n=4047\end{array}$ & $\begin{array}{l}\text { Non-participants, } \\
n=8310\end{array}$ & $\begin{array}{l}\text { Participants, } \\
n=4533\end{array}$ & $\begin{array}{l}\text { Non-participants, } \\
n=7393\end{array}$ \\
\hline \multicolumn{7}{|l|}{ Gender, $n(\%)$} \\
\hline Women & $4533(52.8)$ & $7393(47.1)$ & & & & \\
\hline Men & $4047(47.2)$ & $8310(52.9)$ & & & & \\
\hline Occupation, $n(\%)$ & 8574 & 15,623 & 4043 & 8260 & 4531 & 7363 \\
\hline $\begin{array}{l}\text { Medium to highly skilled } \\
\text { employment }\end{array}$ & $1735(20.2)$ & $1735(11.1)$ & $651(16.1)$ & $783(9.5)$ & $1084(23.9)$ & $952(12.9)$ \\
\hline $\begin{array}{l}\text { Self-employed/family } \\
\text { worker }\end{array}$ & $422(5.0)$ & $514(3.3)$ & $294(7.3)$ & $365(4.4)$ & $128(2.8)$ & $149(2.0)$ \\
\hline $\begin{array}{l}\text { Low to unskilled } \\
\text { employment }\end{array}$ & $2609(30.4)$ & $4592(29.4)$ & $1372(33.9)$ & $2870(34.7)$ & $1237(27.3)$ & $1722(23.4)$ \\
\hline $\begin{array}{l}\text { Unemployed/under } \\
\text { education/other }\end{array}$ & $564(6.3)$ & $1934(12.4)$ & $218(5.4)$ & 984 (11.9) & $346(7.6)$ & $950(12.9)$ \\
\hline $\begin{array}{l}\text { Retired early due to } \\
\text { invalidity }\end{array}$ & $361(4.2)$ & $1363(8.7)$ & $145(3.6)$ & $661(8.0)$ & $216(4.8)$ & $702(9.5)$ \\
\hline Retired & $2634(30.7)$ & $4372(27.9)$ & $1284(31.8)$ & $2048(24.8)$ & $1350(29.8)$ & $2324(32.5)$ \\
\hline Social benefit recipient & $249(2.9)$ & $1113(7.1)$ & $79(1.9)$ & $549(6.6)$ & $170(3.7)$ & $564(7.7)$ \\
\hline Civil status, $n(\%)$ & 8543 & 15,424 & 4028 & 8136 & 4515 & 7288 \\
\hline Married/partnership & $5481(64.2)$ & $7288(47.2)$ & $2635(65.4)$ & $3762(46.2)$ & $2847(63.1)$ & $3526(48.4)$ \\
\hline Divorced & $951(11.1)$ & $1838(11.9)$ & $433(10.7)$ & $886(10.9)$ & $518(11.5)$ & $952(13.1)$ \\
\hline Widow/widower & $390(4.6)$ & $1033(6.7)$ & $110(2.7)$ & $253(3.1)$ & $280(6.2)$ & $780(10.7)$ \\
\hline Single & $1720(20.1)$ & $5265(34.1)$ & $850(21.1)$ & $3235(39.8)$ & $870(19.3)$ & $2030(27.8)$ \\
\hline Type of household, $n(\%)$ & 8543 & 15,424 & 4028 & 8136 & 4515 & 7288 \\
\hline Single man & $575(6.7)$ & $1702(11.0)$ & $570(14.1)$ & $1687(20.7)$ & $5(0.1)$ & $15(0.2)$ \\
\hline Single woman & $807(9.4)$ & $1973(12.8)$ & $19(0.5)$ & $74(0.9)$ & $788(17.4)$ & $1899(26.1)$ \\
\hline Married couple & $5198(60.8)$ & $6635(43.0)$ & $2511(62.3)$ & 3447 (42.4) & $2687(59.5)$ & $3188(43.7)$ \\
\hline Couple, other & $1211(14.2)$ & $2540(16.5)$ & $551(13.7)$ & $1346(16.5)$ & $660(14.6)$ & $1194(16.4)$ \\
\hline Other with more families & $752(8.8)$ & $2573(16.7)$ & $377(9.4)$ & $1582(19.4)$ & $375(8.3)$ & $991(13.6)$ \\
\hline Citizenship, $n(\%)$ & 8580 & 15,703 & 4047 & 8310 & 4533 & 7393 \\
\hline Non-Danish & $231(2.7)$ & $1017(6.5)$ & $88(2.2)$ & $532(6.4)$ & $143(3.1)$ & $485(6.5)$ \\
\hline Danish & 8349 (97.3) & $14,686(93.5)$ & $3959(97.8)$ & $7778(93.6)$ & $4390(96.8)$ & $6908(93.4)$ \\
\hline $\begin{array}{l}\text { Taxable income } \\
\text { (DKK/year), } n(\%)\end{array}$ & 8574 & 15,623 & 4043 & 8260 & 4531 & 7363 \\
\hline 1st quartile $(0-134,672)$ & $1572(18.3)$ & $4477(28.7)$ & $640(15.8)$ & $2264(27.4)$ & $932(20.6)$ & $2213(30.1)$ \\
\hline $\begin{array}{l}\text { 2nd quartile } \\
\qquad(134,672-189,012)\end{array}$ & $1787(20.8)$ & $4262(27.3)$ & $741(18.3)$ & $1967(23.8)$ & $1046(23.1)$ & $2295(31.2)$ \\
\hline $\begin{array}{l}\text { 3rd quartile } \\
\quad(189,012-261,430)\end{array}$ & $2244(26.2)$ & $3805(24.4)$ & $967(23.9)$ & $2036(24.6)$ & $1277(28.2)$ & $1769(24.0)$ \\
\hline 4 th quartile $(>261,430)$ & $2971(34.6)$ & 3079 (19.7) & $1695(41.9)$ & $1993(24.1)$ & $1276(28.2)$ & $1086(14.7)$ \\
\hline \multicolumn{7}{|c|}{ Taxable income (DKK/year), $n(\%)$} \\
\hline $\begin{array}{l}\text { Mean } \pm \text { SD taxable } \\
\text { income }\end{array}$ & $242,722 \pm 391,568$ & $194,524 \pm 147,061$ & $269,052 \pm 408,676$ & $208,523 \pm 178,308$ & $219,228 \pm 287,816$ & $178,818 \pm 98,782$ \\
\hline $\begin{array}{l}\text { Highest achieved } \\
\quad \text { education, } n(\%)\end{array}$ & 8355 & 15,020 & 3887 & 7792 & 4317 & 6973 \\
\hline Basic education & $2041(24.4)$ & $5962(39.7)$ & $905(23.3)$ & $3017(38.7)$ & $1136(26.3)$ & $2945(42.2)$ \\
\hline Vocational education & $483(5.9)$ & $1081(7.3)$ & $338(8.7)$ & $699(9.0)$ & $145(3.4)$ & $382(5.5)$ \\
\hline Short higher education & $128(1.5)$ & $257(1.7)$ & $65(1.7)$ & $163(2.1)$ & $63(1.5)$ & $94(1.3)$ \\
\hline $\begin{array}{l}\text { Medium higher } \\
\text { education }\end{array}$ & $3404(40.7)$ & $4937(33.4)$ & $1958(50.4)$ & $3125(40.1)$ & $1446(33.5)$ & $1812(26.0)$ \\
\hline Long higher education & $2148(25.7)$ & $2528(17.1)$ & $621(16.0)$ & $788(10.1)$ & $1527(35.4)$ & $1740(24.9)$ \\
\hline
\end{tabular}

$S D$ standard deviation 
years $(47.5 \%)$ and $50-59(45.5 \%)$, followed by men aged 60-69 years $(44.7 \%)$. Participation rates in children were lowest in infants aged $0-1$ years $(23.5 \%$ for girls and $24.5 \%$ for boys), and ranged from $27.5 \%$ in boys aged $11-17$ years to $32.2 \%$ in girls aged $2-10$ years. Below the age of 70 years, participation rates were higher in adult women compared to adult men, whereafter men were more likely to participate.

Of 24,283 subjects aged 18 years and above who were selected for invitation to participate in LOFUS between 29 Jan 2016 and 1 Jun 2018, 8580 (35.3\%) participated, of whom 4533 (52.8\%) were women (Table 2). Participants were more likely to be employed (medium to highly skilled or selfemployed), retired, married, Danish citizens, have income above 189,012 Danish crowns (DKK)/year (one US dollar is equivalent to $6.5 \mathrm{DKK}$ ), and have medium/long higher education, and less likely to be unemployed, have retired early due to invalidity, receive social benefits, be single, be widow/ widowers, be divorced, and live in a household with other families, than non-participants.

Men had statistically significant lower odds of participating in LOFUS than women (OR: 0.79 ; $95 \%$ CI: $0.75-$ 0.84) (Table 3). Compared to medium to highly skilled employed persons, individuals with all other occupations had statistically significant lower odds of participating in LOFUS, with the lowest odds observed in unemployed persons/individuals being under education (OR: 0.29; 95\% CI: $0.26-0.33$ ), persons retired early due to invalidity (OR: 0.26 ; 95\% CI: $0.23-0.30$ ), and recipients of social benefits (OR: 0.22 ; 95\% CI: $0.19-0.26$ ). Similar patterns were observed in gender-specific analyses, with the lowest participation rate observed in men receiving social benefits (OR: 0.17 ; 95\% CI: 0.13-0.22). Compared to individuals who were married or living in partnership, divorced persons (OR: 0.69; 95 CI: 0.63-0.75), widows/widowers (OR: 0.50; 95 CI: 0.44-0.57), and individuals living alone (OR: 0.43 ; 95 CI: $0.41-0.46$ ) all had statistically significantly lower odds of participation in LOFUS. Similarly, compared to households consisting of married couples, all other types of households had statistically significantly lower odds of participating in LOFUS: single men (OR: 0.43; 95\% CI: $0.39-0.48$ ), single women (OR: $0.52 ; 95 \%$ CI: 0.48-0.57), couples not married (OR: $0.61 ; 95 \%$ CI: $0.56-0.66$ ), and households with several members (OR: 0.37; 95\% CI: 0.34-0.41). Compared to individuals with taxable income $<137,672$ DKK/year, the odds of participating in LOFUS increased with increasing income, with the highest odds in those earning $>261,430$ DKK/year (OR: 2.75; 95\% CI: 2.55-2.97). Compared to persons with basic education, the odds of participating in LOFUS increased with increasing education level, with the highest odds in those with long higher education (OR: 2.48; $95 \%$ CI: $2.30-2.68)$.

\section{Discussion}

Approximately halfway through the LOFUS data collection, we have detected a $34.1 \%$ participation rate. For both men and women, the participation rate was highest in the age group 60 69 years (44.7\% in men and $47.5 \%$ in women) and lowest in the age group $\geq 90$ years (9.5\% in men and $7.3 \%$ in women). We found considerable differences between participants and non-participants in LOFUS, with overall higher participation rates among individuals of higher socio-economic status. Middle-aged, married, employed, and retired persons with higher education and income, and Danish citizens were overrepresented in LOFUS.

The overall participation rate of $34.1 \%$ observed in LOFUS for all ages is comparable to the $35 \%$ rate in the Danish Diet, Cancer and Health study, which focused on subjects aged 5064 years, with participation rate ranging from $32 \%$ (men aged 60-64 years) to $40 \%$ (women aged 50-54 years) (Tjønneland et al. 2007). In the age group 50-69 years, LOFUS had higher participation rates, $36.3-44.7 \%$ in men and $45.5-47.5 \%$ in women compared to $34 \%$ in men and $37 \%$ in women in the Danish Diet, Cancer and Health cohort, respectively (Tjønneland et al. 2007), indicating possibly higher participation rates in rural than highly urban areas of Denmark. The household design of LOFUS may have affected participation rates, as all household members are invited to participate, which may influence the incentive to participate. Furthermore, the mode of invitation and re-invitation (eBoks or mail) probably increased the chance that at least someone in a household discovered that they were invited and encouraged other household members to participate. LOFUS had lower participation rates than the Copenhagen City Heart Study and the Danish Nurse Cohort, where $76 \%$ and 76-86\% of invited subjects participated, respectively (Aguib and Al Suwaidi 2015; Hundrup et al. 2012). Participation rates differ between cohorts depending on a number of factors. The LifeLines cohort in the Netherlands, a three-generation cohort study from 2006 and 2013, which, in line with LOFUS, included participants of all ages, recruited index persons (aged 25-49 years) via general practitioners and subsequently included their younger and older family members. Amongst eligible index persons, $24.5 \%$ participated, whilst $70.2 \%$ of subjects invited via family participated (Scholtens et al. 2015). The Scottish Family Health Study (GS:SFHS), which recruited participants between 2006 and 2011, randomly identified index persons (in the beginning aged 36-65 years and later aged 18-65 years) via general practitioners and invited them to participate together with at least one adult relative. The participation rate was only 5.3\% for the index persons (Smith et al. 2013). A similarly low participation rate was found in the UK Biobank, which, between 2006 and 2010, sent postal invitations to more than 9 million people $40-69$ years of age, of whom $5.4 \%$ visited a 
Table 3 Association between socio-economic factors and participation in the Lolland-Falster Health Study

\begin{tabular}{|c|c|c|c|}
\hline & $\begin{array}{l}\text { Total } \\
\text { OR }(95 \% \mathrm{CI})\end{array}$ & $\begin{array}{l}\text { Men } \\
\text { OR }(95 \% \text { CI })\end{array}$ & $\begin{array}{l}\text { Women } \\
\text { OR }(95 \% \mathrm{CI})\end{array}$ \\
\hline \multicolumn{4}{|l|}{ Gender $^{\mathrm{a}}$} \\
\hline Women & 1.00 & - & - \\
\hline Men & $0.79(0.75-0.84)$ & & \\
\hline \multicolumn{4}{|l|}{ Occupation $^{\mathrm{b}}$} \\
\hline Medium to highly skilled employment & 1.00 & 1.00 & 1.00 \\
\hline Self-employed/family worker & $0.82(0.71-0.95)$ & $0.97(0.80-1.17)$ & $0.75(0.59-0.97)$ \\
\hline Low to unskilled employment & $0.57(0.52-0.62)$ & $0.57(0.51-0.65)$ & $0.63(0.56-0.71)$ \\
\hline Unemployed/under education/other & $0.29(0.26-0.33)$ & $0.27(0.22-0.32)$ & $0.32(0.28-0.37)$ \\
\hline Retired early due to invalidity & $0.26(0.23-0.30)$ & $0.26(0.21-0.32)$ & $0.27(0.23-0.32)$ \\
\hline Retired & $0.60(0.55-0.65)$ & $0.75(0.67-0.85)$ & $0.51(0.46-0.57)$ \\
\hline Social benefit recipient & $0.22(0.19-0.26)$ & $0.17(0.13-0.22)$ & $0.26(0.22-0.32)$ \\
\hline \multicolumn{4}{|l|}{ Civil status $^{\mathrm{b}}$} \\
\hline Married/partnership & 1.00 & 1.00 & 1.00 \\
\hline Divorced & $0.69(0.63-0.75)$ & $0.70(0.61-0.79)$ & $0.67(0.60-0.76)$ \\
\hline Widow/widower & $0.50(0.44-0.57)$ & $0.62(0.49-0.78)$ & $0.44(0.38-0.51)$ \\
\hline Single & $0.43(0.41-0.46)$ & $0.38(0.34-0.41)$ & $0.53(0.48-0.58)$ \\
\hline \multicolumn{4}{|l|}{ Type of household ${ }^{b}$} \\
\hline Single man & $0.43(0.39-0.48)$ & - & - \\
\hline Single woman & $0.52(0.48-0.57)$ & & \\
\hline Married couple & 1.00 & & \\
\hline Couple, other & $0.61(0.56-0.66)$ & & \\
\hline Other with more families & $0.37(0.34-0.41)$ & & \\
\hline \multicolumn{4}{|l|}{ Citizenship $^{\mathrm{b}}$} \\
\hline Non-Danish & 1.00 & 1.00 & 1.00 \\
\hline Danish & $2.50(2.16-2.89)$ & $3.08(2.45-3.87)$ & $2.16(1.78-2.61)$ \\
\hline \multicolumn{4}{|l|}{ Taxable income $^{\mathrm{b}}$ (DKK/year) } \\
\hline 1st quartile $(0-134,672)$ & 1.00 & 1.00 & 1.00 \\
\hline 2nd quartile $(134,672-189,012)$ & $1.19(1.10-1.29)$ & $1.33(1.18-1.51)$ & $1.08(0.97-1.20)$ \\
\hline 3rd quartile $(189,012-261,430)$ & $1.68(1.55-1.82)$ & $1.68(1.49-1.89)$ & $1.71(1.54-1.90)$ \\
\hline 4th quartile $(>261,430)$ & $2.75(2.55-2.97)$ & $3.01(2.70-3.36)$ & $2.79(2.50-3.12)$ \\
\hline \multicolumn{4}{|l|}{ Highest achieved education $^{\mathrm{b}}$} \\
\hline Basic education & 1.00 & 1.00 & 1.00 \\
\hline Vocational education & $1.31(1.16-1.47)$ & $1.61(1.39-1.87)$ & $0.98(0.80-1.21)$ \\
\hline Short higher education & $1.45(1.17-1.81)$ & $1.33(0.99-1.79)$ & $1.74(0.25-2.41)$ \\
\hline Medium higher education & $2.01(1.88-2.15)$ & $2.09(1.90-2.29)$ & $2.07(1.88-2.28)$ \\
\hline Long higher education & $2.48(2.30-2.68)$ & $2.63(2.31-2.99)$ & $2.27(1.06-2.51)$ \\
\hline
\end{tabular}

$O R$ odds ratio; $C I$ confidence intervals for $\mathrm{OR}$

a Adjusted for age

${ }^{\mathrm{b}}$ Adjusted for age and gender

study center and provided data by questionnaires, physical examination, and biological samples (Fry et al. 2017). Participation rates in epidemiological studies have generally declined over time, possibly due to increasingly extensive and demanding data collection, with physical examinations, blood, urine, feces samples, spirometry test, physical activity measurements, etc. (Galea and Tracy 2007; Krokstad et al.
2013). In the area of Lolland-Falster, it is the first time that a general population cohort study has been conducted. It may take time for the population to familiarize with such an initiative, and participation rates may thus increase throughout the 4 years of recruitment.

We found that a number of socio-economic factors determined participation in LOFUS and then, in general, 
individuals who are middle-aged, married, and Danish citizens and those with higher socio-economic status (higher education, higher income, and employment) are more likely to participate. Our findings are directly comparable to those from the study by Tjønneland et al. (2007) from the Danish Diet, Cancer and Health study, which used the same approach as our study and extracted data on socio-economic determinants from the same national Danish registers. Tjønneland et al. (2007) found, in line with our results, that subjects who were married, had higher income, had higher education, were employed, and lived in large single-family houses were more likely to participate, with effect estimates almost identical to ours. This implies that, even in the socio-economically disadvantaged mixed rural-urban areas such as Lolland-Falster, drivers of participation in a cohort study are more or less the same as in urban areas, with overrepresentation of subjects with higher socio-economic status. These general participation trends have also been documented in other studies, which found that being female (Klijs et al. 2015; Langhammer et al. 2012; Smith et al. 2013), middle-aged (Klijs et al. 2015; Langhammer et al. 2012; Smith et al. 2013), married (Klijs et al. 2015; Langhammer et al. 2012), highly educated (Klijs et al. 2015; Langhammer et al. 2012; Smith et al. 2013), richer (Klijs et al. 2015; Langhammer et al. 2012; Smith et al. 2013), in work (Smith et al. 2013), not receiving social benefits (Langhammer et al. 2012; Smith et al. 2013), and belonging to the majority in terms of country of origin (Klijs et al. 2015; Smith et al. 2013) increased the likelihood of participation.

If non-participation is associated with disease, as is often the case with people with lower socio-economic position and poorer lifestyle (higher smoking and alcohol consumption rates, higher body mass index, lower physical activity, etc.) (Galea and Tracy 2007; Langhammer et al. 2012), fewer resources, and poorer access to healthcare leading to higher morbidity and mortality, then both exposure and disease may be underrepresented (Galea and Tracy 2007; Rothman et al. 2008). This may, in turn, lead to bias in the estimation of causal associations between exposures and diseases in cohorts with this unintentional selection, as is the case in LOFUS. However, it has been documented that this type of selection bias can be effectively controlled for by adjusting for the socio-economic determinants as well as other confounders, such as age, gender, lifestyle (smoking, alcohol use, body mass index, etc.) in the estimation of certain exposure-outcome associations, giving unbiased estimates (Lesko et al. 2017).

\section{Methodological considerations}

The major strength of our study is the linkage of participants and non-participants, using their personal identification number, to various socio-economic determinants in the nationwide registers, which is feasible only in a few countries apart from
Denmark. Data from these registers on income, education, and employment are part of the Danish national official statistics and are highly valid and almost complete (Baadsgaard and Quitzau 2011; Petersson et al. 2011; Jensen and Rasmussen 2011), facilitating a unique opportunity to study associations between different socio-economic drivers and participation patterns in a cohort study. Furthermore, our study is unique in the sense that determinants of participation in a socioeconomically deprived, mainly rural area have been described, perhaps for the first time, documenting as a novel finding that participation determinants do not seem to differ from other studies in highly urban or socio-economically more privileged areas.

A weakness of our study is that information on education, occupation, and income is registered in Denmark only, and, for example, education or part-time job with income in other countries or education abroad outside the Danish public educational system are not registered. Furthermore, most of the socio-economic factors included in this study are highly correlated, including education, occupation, and income, which is why we decided not to include them in the multivariate model, adjusting for each other, but to estimate the individual impact of each variable on the participation in LOFUS. We lack information on other important determinants of participation in a cohort study, such as personal lifestyle characteristics. Some deviation from the results in this halfway study may be expected once the study has been completed.

\section{Conclusions}

Halfway through the LOFUS data collection, we have detected a $34.1 \%$ participation rate in LOFUS, with the highest participation rate in women aged 60-69 years $(47.5 \%)$ and the lowest in women aged $\geq 90$ years $(7.9 \%)$. We found significantly higher participation of women and individuals of higher socio-economic status, implying that people of lower socio-economic status were underrepresented in LOFUS, in line with other cohort studies.

Acknowledgements LOFUS is funded by Region Zealand, Nykøbing Falster Hospital, and Lolland and Guldborgsund municipalities. The authors are grateful for permission to use the LOFUS data. The analysis and interpretation of the LOFUS data presented in this paper are the sole responsibility of the authors. The authors would like to thank the inhabitants of Lolland-Falster, the LOFUS staff for their commitment to the study, and Elsebeth Lynge for inspiration and support.

\section{Compliance with ethical standards}

Ethical approval All procedures performed in this study were in accordance with the ethical standards of Region Zealand's Ethical Committee on Health Research (SJ-421) and with the 1964 Helsinki declaration and its later amendments or comparable ethical standards. 
Informed consent Informed consent was obtained from all individual participants included in the study.

Conflict of interest The authors declare that they have no conflict of interest.

Declaration of competing interests The authors declare that they have no competing interests.

Open Access This article is distributed under the terms of the Creative Commons Attribution 4.0 International License (http:// creativecommons.org/licenses/by/4.0/), which permits unrestricted use, distribution, and reproduction in any medium, provided you give appropriate credit to the original author(s) and the source, provide a link to the Creative Commons license, and indicate if changes were made.

\section{References}

Aguib Y, Al Suwaidi J (2015) The Copenhagen City Heart Study (Østerbroundersøgelsen). Glob Cardiol Sci Pract. https://doi.org/ $10.5339 / \mathrm{gcsp} .2015 .33$

Baadsgaard M, Quitzau J (2011) Danish registers on personal income and transfer payments. Scand J Public Health 39(7 Suppl):103-105

e-Boks (2017) What is e-Boks? e-Boks, Copenhagen https://www.eboks.com/danmark/en/what-is-e-boks. Accessed 21 Dec 2018

Fry A, Littlejohns TJ, Sudlow C et al (2017) Comparison of sociodemographic and health-related characteristics of UK Biobank participants with those of the general population. Am J Epidemiol 186(9):1026-1034

Galea S, Tracy M (2007) Participation rates in epidemiologic studies. Ann Epidemiol 17(9):643-653

Hundrup YA, Simonsen MK, Jørgensen T, Obel EB (2012) Cohort profile: the Danish nurse cohort. Int J Epidemiol 41(5):1241-1247

Jensen VM, Rasmussen AW (2011) Danish education registers. Scand J Public Health 39(7 Suppl):91-94

Jepsen R, Egholm CL, Brodersen J et al (2018) Lolland-Falster Health Study: study protocol for a household-based prospective cohort study. Scand J Public Health. https://doi.org/10.1177/ 1403494818799613
Klijs B, Scholtens S, Mandemakers JJ et al (2015) Representativeness of the LifeLines cohort study. PLoS One. https://doi.org/10.1371/ journal.pone. 0137203

Krokstad S, Langhammer A, Hveem K et al (2013) Cohort profile: the HUNT study, Norway. Int J Epidemiol 42(4):968-977

Langhammer A, Krokstad S, Romundstad P et al (2012) The HUNT study: participation is associated with survival and depends on socioeconomic status, diseases and symptoms. BMC Med Res Methodol 12:143. https://doi.org/10.1186/1471-2288-12-143

Lesko CR, Buchanan AL, Westreich D et al (2017) Generalizing study results: a potential outcomes perspective. Epidemiology 28(4):553561

Petersson F, Baadsgaard M, Thygesen LC (2011) Danish registers on personal labour market affiliation. Scand J Public Health 39(7 Suppl):95-98

Rothman KJ, Greenland S, Lash TL (2008) Validity in epidemiologic studies. In: Rothman KJ, Greenland S, Lash TL (eds) Modern epidemiology, 3rd edn. Lippincott Williams \& Wilkins, Philadelphia, pp 128-147

Schmidt M, Pedersen L, Sørensen HT (2014) The Danish Civil Registration System as a tool in epidemiology. Eur J Epidemiol 29(8):541-549

Scholtens S, Smidt N, Swertz MA et al (2015) Cohort profile: LifeLines, a three-generation cohort study and biobank. Int J Epidemiol 44(4): $1172-1180$

Smith BH, Campbell A, Linksted P et al (2013) Cohort profile: Generation Scotland: Scottish Family Health Study (GS:SFHS). The study, its participants and their potential for genetic research on health and illness. Int J Epidemiol 42(3):689-700

Thygesen L (1995) The register-based system of demographic and social statistics in Denmark - an overview. Stat J U N Econ Comm Eur 12(1):49-55

Tjønneland A, Olsen A, Boll K et al (2007) Study design, exposure variables, and socioeconomic determinants of participation in Diet, Cancer and Health: a population-based prospective cohort study of 57,053 men and women in Denmark. Scand J Public Health 35(4): $432-441$

Publisher's note Springer Nature remains neutral with regard to jurisdictional claims in published maps and institutional affiliations. 